\title{
Factor Analysis of Greenhouse Gas Emissions from Automobiles
}

\author{
John M. DeCicco \\ University of Michigan Energy Institute and \\ School of Natural Resources and Environment \\ Working Paper \\ December 2012
}

\begin{abstract}
Three approaches are commonly identified for controlling automobile greenhouse gas (GHG) emissions: reducing travel demand, improving vehicle efficiency and using alternatively (nonpetroleum) fueled vehicles (AFVs). Similarly, sector emissions can be decomposed by travel distance, vehicle fuel intensity and fuel GHG ("carbon") intensity. Normalized analysis of these three factors offers valuable insights. For a broad set of conditions, any stringent GHG emissions limit for the automobile sector implies a limit of comparable stringency for fuel carbon intensity. However, carbon intensity is an abstraction of complex supply systems rather than an observable property of fuels (physical energy carriers) themselves. Carefully considering the locations and current magnitudes of fuel-related emissions implies that the proper policy focus is on upstream sectors that supply fuel rather than the choice of fuels downstream in the auto sector. Therefore, other than fundamental R\&D, programs to promote AFVs are not currently warranted for climate protection. In addition to managing travel demand and improving vehicle efficiency, the implied climate policy priority is limiting net GHG emissions in fuel supply sectors. Future work is needed to develop GHG management policies for liquid fuel supply systems involving fungible commodities and dynamic global supply chains.
\end{abstract}




\section{Table of Contents}

1. Introduction 1

1.1 The auto and fuel markets 1

1.2 Approaching the challenge 3

2. Factorization Methods 4

2.1 Determinants of emissions from cars 5

2.2 Normalized Factors 6

3. Analysis 9

3.1 Factor Trends

3.2 Future Expectations 12

3.3 Normalized Scenarios 14

4. Discussion 18

4.1 Focusing on the location of emissions 19

4.2 Implications of a source-based framework 20

$\begin{array}{ll}4.3 \text { Questioning the case for AFVs } & 21\end{array}$

5 Conclusion 23

$\begin{array}{ll}\text { Acknowledgements } & 25\end{array}$

$\begin{array}{ll}\text { Endnotes } & 25\end{array}$

$\begin{array}{ll}\text { References } & 26\end{array}$ 


\section{Introduction}

Transportation is a major economic activity in its own right as well as a system that supports and connects other areas of human activity. In terms of greenhouse gas (GHG) emissions, cars comprise the largest transportation subsector, particularly in mature economies such as the United States and other members of the Organization for Economic Cooperation and Development (OECD). While freight still dominates transportation energy use and emissions in China and other developing economies, car use is growing rapidly as rising incomes enable increasing levels of car ownership and personal mobility.

As of 2005, global transportation energy use was just over 100 exajoules (EJ) annually, corresponding to petroleum demand of 46 million barrels per day (Mbd) and accounting for about $25 \%$ of total world energy use (IEA 2009). Global GHG emissions from transportation were 6.4 petagrams (Pg, $10^{15} \mathrm{~g} \mathrm{CO}_{2}$-equivalent, in direct [end-use] terms), or $17 \%$ of world total anthropogenic GHG emissions of 38 Pg in 2005 (Schäfer et al. 2009, p. 14). An assessment of time-integrated radiative forcing shows that, as of 2000 , transportation is responsible for $19 \%$ of anthropogenic forcing incurred over a period through 2100 (Unger et al. 2010).

Of the global transportation total, $61 \%$ of $\mathrm{CO}_{2}$ emissions (3.9 Pg) was related to passenger travel (mainly by cars) as opposed to freight. Passenger travel shares were $70 \%$ in the United States while in China the passenger share of overall travel is still notably lower, on the order of $40 \%$ (Schäfer et al. 2009). Here "car" is used synonymously with automobile or light duty vehicle ("LDV"). This category includes most light trucks, e.g., those up to 3,900 kg (8,500 lb gross vehicle weight in U.S. agency statistics), including passenger vans, sport-utility vehicles and light pickups. U.S. automobile use alone accounted for $1.2 \mathrm{Pg}$ of $\mathrm{CO}_{2}$ emissions in 2005 (EPA 2007), or about 30\% of the global total due to passenger travel. As economic development progresses, greater personal mobility is expected in line with historical correlations between travel and income (Schäfer et al. 2009, p. 36). By 2050, passenger travel is projected to rise by a factor of 1.4 in the OECD and by a factor of 3.3 in the non-OECD, with most growth occurring as car use (IEA 2009, p. 211).

\subsection{The auto and fuel markets}

The car is a highly desired and indeed aspirational consumer product, with layers of meaning that go well beyond its utilitarian functions. As a result, automaking is a high value-added industry and many nations support their auto sector for its role in fostering economic growth (job 
creation) as much as for its role in providing mobility. This century-old paradigm is alive and well in major emerging economies such as China, Brazil, Russia and India. China views its auto industry among its pillars of economic development; the country has overtaken the United States in new car sales and is on track to become the world's largest center of motor vehicle manufacturing (An 2010).

Because of the high value placed on personal vehicles by individuals, consumers willingly capitalize the automotive sector's rolling stock. A major portion of the system is thereby privately financed, an important distinction between automobiles and other forms of transport. For public transit, intercity rail and bus services or commercial air, vehicle stocks must be capitalized by operating entities (public agencies, private businesses or public-private partnerships) and face perennial economic challenges. The high value placed on cars fosters a modal structure, including associated land-use patterns, roadways and other infrastructure, that favors automobiles over other modes except in urban areas that have maintained substantial public investments and other measures to encourage automobile alternatives. At least in the United States this paradigm, which some critically call automobile dependency but most policymakers support, provides a robust "benefits regime" for personal mobility that is reasonably equitable and economically efficient (Dunn 1998).

The liquid hydrocarbon fuels such as gasoline and diesel that now almost exclusively propel cars are also highly valued, but the nature of their market is quite different than that of the car market. Liquid fuels have a high energy density and are easy to transport. These same traits that make them so well suited for motor vehicles also make them fungible, globally traded commodities. Consumers differentiate fuels mainly by price, with quality taken for granted given the commercial standards that define fuel products. Fungibility enables secondary markets and speculation; scale economies and other factors (notably the geographic concentration of the resource) make such markets vulnerable to monopoly behaviors. Thus, motor fuels are commodity products tied to the volatile, cartelized world market for a commodity resource, oil, that is a longstanding concern for security reasons.

Although oil has strategic importance, for consumers fuel is simply a cost to be minimized. Its strictly utilitarian valuation is quite different from the aspirational and emotional levels of meaning attached to automobiles, which sustain transutilitarian pricing in the car market. Except during price spikes, fuel costs generally are a relatively small share of the total cost of owning and operating a car. Where fuel taxes are high, as in Europe, the consumer cost 
share is of course greater than where they are low, as in the United States. But the economic (resource) cost of fuel is still small compared to a car's capital cost and other expenses. Using data for 2010, when fuel prices were higher than the previous decade's average, fuel including tax was $16 \%$ of the average annualized operating cost for a U.S. automobile, compared to $47 \%$ for depreciated capital costs, 30\% for finance, insurance and non-fuel-related fees and taxes, and 7\% for maintenance (Ward's 2010). In contrast to the many layers of value placed on a personal vehicle, consumers place no more value on a fuel than its utility for propulsion.

\subsection{Approaching the challenge}

This backdrop frames the challenge of limiting transportation GHG emissions, a question that has been analyzed for many years. A sample of mainly U.S. studies includes: OTA (1991); PDAC (1996); DeCicco \& Mark (1998); WBCSD (2004); Cambridge Systematics (2009); IEA (2009); McCollum \& Yang (2009); Schäfer et al. (2009); Melaina \& Webster (2011). These analyses typically start with the three factors of travel demand, vehicle efficiency and fuel characteristics, and then focus on technology scenarios or "pathways," particular combinations of vehicle types and alternative fuels, for reducing emissions.

A deeply embedded set of assumptions underpins the nearly universal recommendation for policies to foster adoption of alternative fuels and vehicles (AFVs), meaning non-petroleum fuels and vehicles capable of using them. Extensively researched and variously subsidized over the years, AFV options include: electricity (for battery cars or plug-in hybrids), hydrogen (for fuel cell cars), natural gas, and bioenergy, including ethanol and other biofuels that can be used in combustion engines or as a renewable feedstock for producing electricity or hydrogen. Most studies identify AFVs as one of the "three legs of the stool" for transportation climate policy that, along with vehicle efficiency and travel demand reduction, are essential for reducing emissions.

This paper takes a fundamental look at the situation, independent of particular technology options, in order to critically examine established approaches. It deliberately analyzes the sector only from a GHG emissions perspective, rather than from the politically more popular perspective of reducing oil dependence, to parse out how policy priorities for climate protection might differ from those of energy policy. The emphasis is on the United States, for which the best data are available and which remains the world's largest source of auto-related GHG emissions. The U.S. situation epitomizes the challenges faced if personal mobility continues to develop globally following a similar paradigm. Although data are sparse and projections uncertain, an example is also given for China to examine the implications of rapid growth. 
Nevertheless, it should be kept in mind that many factors could influence mobility systems to evolve in ways that differ from extensive reliance on the highly capable, energy intensive cars of the $20^{\text {th }}$ century that form the basis of most policy analysis, including this paper.

\section{Factorization Methods}

Formally decomposing GHG emissions into factors amenable to measurement is helpful for understanding what influences the sector and is a basis for modeling energy use and emissions. The choice of factors depends on the objectives of study and availability of data. Factor analysis is useful both retrospectively and prospectively. Looking back, it offers insights into how the determinants of energy demand or environmental impact influence observed outcomes. Looking forward as done here, it offers insights into the changes needed for socially desired outcomes.

A general decomposition for examining environmental impacts is the IPAT equation (Impact $=$ Population $\times$ Affluence $\times$ Technology) as discussed by Chertow (2001), Waggoner \& Ausubel (2002) and others. It highlights the roles that growing population (P) and affluence (A) have on the environment and natural resources while reflecting how these effects are mediated (for better or worse) through technology (T). Energy analysts often bundle the P and A factors into an aggregate measure of activity while unbundling $\mathrm{T}$ to distinguish different aspects of technology and their respective impacts. Schipper et al. (1992) use what they term the ASIF formulation (Activity $\times$ Structure $\times$ Intensity $=$ Fuel consumption), which combines the influences of population and affluence into an observable metric of transportation activity. Of course, interdependencies exist among the factors regardless of the formulation.

When climate is of concern, the T in IPAT can be decomposed into subfactors, one of which characterizes the GHG emissions impact of energy use. A form of decomposition known as the Kaya equation (e.g., Raupach et al. 2007) is given by:

$$
\text { GHG emissions }=\mathrm{P} \cdot(\mathrm{GDP} / \mathrm{P}) \cdot(\text { Energy } / \mathrm{GDP}) \cdot(\text { Carbon } / \text { Energy })
$$

Here affluence is represented by gross domestic product (GDP) per capita and technology is factored into the energy intensity of the economy and the carbon intensity of energy. Globally, population and affluence continually grow. A retrospective analysis shows that previous declining trends in energy/GDP and carbon intensity halted around 2002, when China's economy in particular was accelerating. Both of these technology-related intensity factors are now increasing (Raupach et al. 2007). On a global average basis, all factors are trending upward though at different rates by factor and by region. 


\subsection{Determinants of emissions from cars}

For analyzing transportation-related GHG emissions, a key observable is transportation activity, such as the aggregate travel distance measured by vehicle miles of travel (VMT). Determinants of VMT include income and settlement patterns as well as the prices of vehicles, fuels, roads, parking and other automobile-supporting infrastructure and services. These factors are both shaped by and influence the share of car use compared to other modes of passenger travel.

Transportation GHG emissions also depend on the energy intensity of vehicles. This metric is also observable and is measured by rates of energy consumption per unit distance, e.g., kilojoules per meter $(\mathrm{kJ} / \mathrm{m})$ or liters per 100 kilometers, which are inversely proportional to fuel economy as measured by miles per gallon (mpg). Automobile energy intensity depends on vehicle design and engineering as well as driving patterns and behavior. These factors are in turn influenced by technological progress, consumer tastes and incomes, fuel prices, operational factors (e.g., road speeds), and policies including vehicle and fuel taxes, incentives and vehicle regulations.

Finally, GHG emissions depend on a "Carbon/Energy" factor as seen in Equation (1). Often given as grams of $\mathrm{CO}_{2}$-equivalent per megajoule $\left(\mathrm{gCO}_{2} \mathrm{e} / \mathrm{MJ}\right)$ as computed by lifecycle analysis (LCA), this factor is commonly termed the carbon intensity of fuel. The terminology preferred here is "fuel system GHG impact." This wording emphasizes that the GHG emissions impacts (including releases as well as uptake or sequestration) pertain to the entire system associated with production and consumption of fuel, including supply chains and related industrial activities as well as the fuel product itself. Although LCA-based "carbon footprints" are widely discussed and fuel carbon intensity has recently become an object of regulation, this factor is the most analytically challenging yet ultimately the most critical aspect of the carclimate problem. Being an abstraction associated with a complex system, carbon intensity is not directly measurable. Carbon intensity is not the same as chemical carbon content; the latter may be included when estimating the former, but not always. For example, biogenic carbon is commonly excluded when calculating the carbon intensity of biofuels, a convention related to the conceptual issues further discussed in Section 4.

These three factors comprise the "three legged stool" that supports GHG emissions from cars. Written concisely, the factorization takes the form:

$$
\mathrm{C}=\mathrm{D} \cdot \mathrm{E} \cdot \mathrm{F}
$$


Here C represents GHG emissions (e.g., tons of $\mathrm{CO}_{2}$-equivalent); D is travel demand activity (e.g., VMT); E is vehicle energy intensity (e.g., $\mathrm{kJ} / \mathrm{m}$ ); and $\mathrm{F}$ is the net GHG emissions impact per unit of fuel energy consumed by the vehicles (e.g., $\mathrm{gCO}_{2} \mathrm{e} / \mathrm{MJ}$ ). This relationship can be viewed as an application of the Kaya equation to auto sector GHG emissions and is similar to Equation 1.1 of Schäfer et al. (2009).

All of the three factors are market outcomes, but the respective markets differ greatly. Cars are sold in a relatively circumscribed market for a distinctive, high-value good. For travel demand, however, the "market" is a complex set of interactions regarding land use, urban form, public-private infrastructure provision and mode choices that shape consumer travel behavior. Scientific understanding of these markets also differs; it depends on the temporal and spatial (geographic) variability that analysts are able to observe. Travel demand analysis is a field unto itself. The auto market is well characterized, with energy intensity being a bundled attribute of car design. The markets for both petroleum (world oil market) and its fuel products (gasoline and diesel) are extensively studied and the prospects for alternative fuels have been analyzed based on limited experience and extensive speculation. However, no market as such has ever existed for carbon in the fuel system and, given the longstanding dominance of petroleum, little or no variability in fuel carbon intensity has been observable.

\subsection{Normalized Factors}

Applying Equation 2 to examine factor values consistent with desired future GHG emissions levels offers insights that are often obscured by methods that focus on particular technologies. It is useful to normalize the factors relative to current conditions; using lowercase letters for the normalized factors and designating the base year with a zero subscript, the definitions are:

$$
c=\mathrm{C} / \mathrm{C}_{0} \quad d=\mathrm{D} / \mathrm{D}_{0} \quad e=\mathrm{E} / \mathrm{E}_{0} \quad f=\mathrm{F} / \mathrm{F}_{0}
$$

Equation (2) then becomes $c=d e f$ in normalized terms. The base year is taken here as 2005, a recent year for which fairly complete data are available.

Using this notation, $c$ can represent the fraction of base year emissions targeted in a future year. For an $80 \%$ reduction, $c=0.20$, for example. Given projected travel demand, tradeoffs between vehicle energy intensity and fuel system GHG impact can be mapped by $f=c / d e$. In other words, for a given GHG emissions target, $f$ and $e$ are inversely related and yield level curves as seen in Figure 1 . The point $(e, f)=(1,1)$ references base year conditions; the curve through it traces other $(e, f)$ values that yield the same emissions. Figure 1 also illustrates a level 


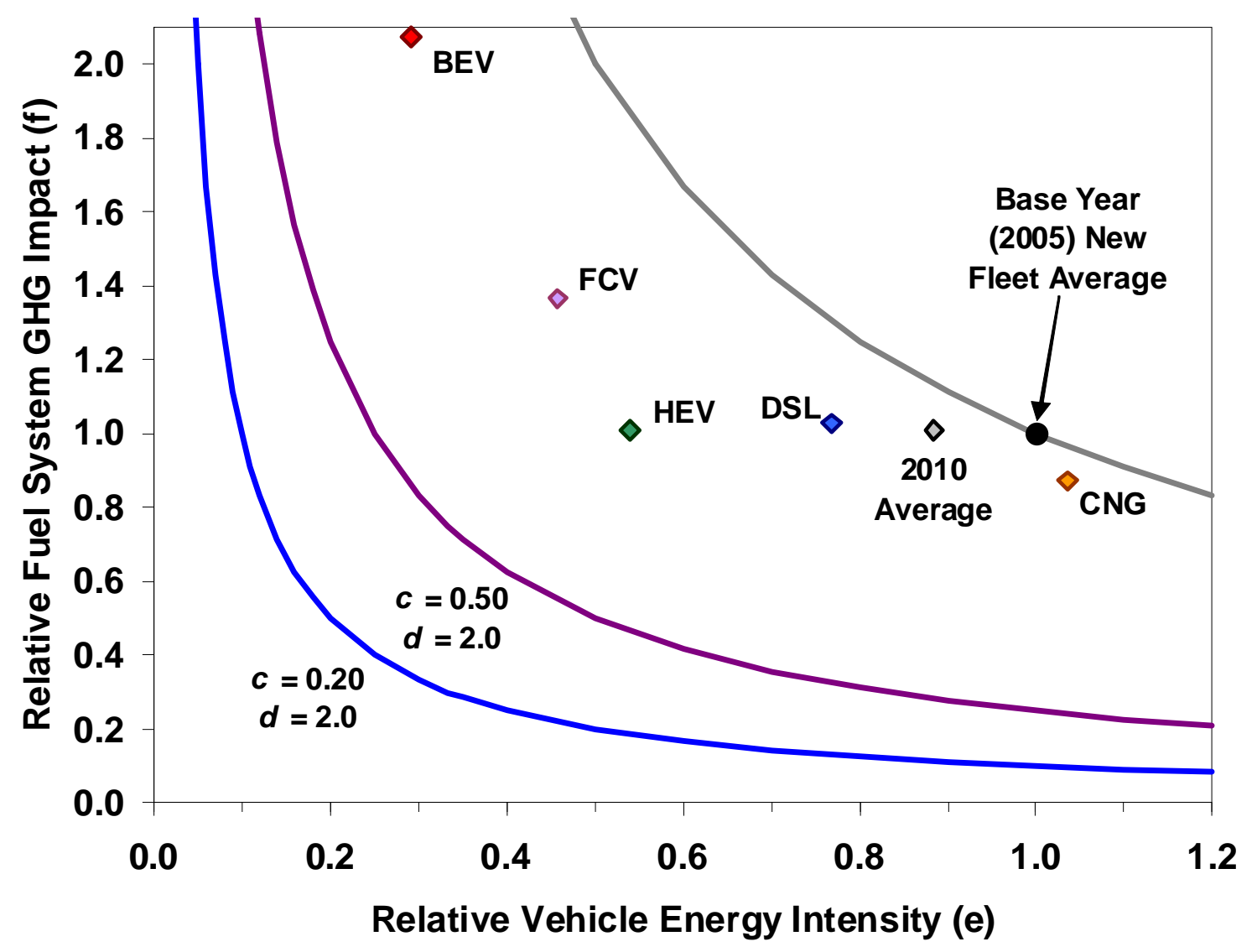

Figure 1. Normalized factor analysis of U.S. auto sector GHG emissions with current vehicle examples as described in text and level curves for illustrative future emissions limits.

curve for an $80 \%$ GHG emissions reduction with a doubling of travel demand $(d=2)$, a plausible high growth scenario for the United States.

Normalized factors provide a way to map the vehicle-fuel system "solution space" for achieving a given level of GHG emissions limitation. It is instructive to plot existing systems relative to a target curve; several examples are shown in Figure 1. The points are for actual contemporary vehicles and represent outcomes that reflect the GHG emissions impact of the respective fuel systems under current conditions. For this interpretation, the vertical $(f)$ axis is normalized to a fuel lifecycle carbon intensity estimate of $92 \mathrm{gCO}_{2} \mathrm{e} / \mathrm{MJ}$, reflecting the U.S. average gasoline system in 2005, rather than an end-use (tailpipe $\mathrm{CO}_{2}$ only) value such as 72 $\mathrm{gCO}_{2} \mathrm{e} / \mathrm{MJ}$, which would be used for a GHG inventory calculation.

The points illustrated include: 
- An average new 2010 U.S. light duty vehicle, with a 12\% fuel economy improvement over the 2005 average of 20 mpg. ${ }^{1}$

- A diesel vehicle (DSL). ${ }^{2}$

- An efficiency-optimized grid-free hybrid electric vehicle (HEV). ${ }^{3}$

- A battery electric vehicle (BEV). ${ }^{4}$

- A hydrogen fuel cell vehicle (FCV). ${ }^{5}$

- A compressed natural gas (CNG) vehicle. ${ }^{6}$

All of these vehicles have lower average GHG emissions than the 2005 fleet average and so fall inside the grey curve. None reflect movement both down and to the left as might be seen if $e$ and $f$ were declining together. Fuel carbon intensity is up in all cases except for $\mathrm{CNG}^{7}$ in which case energy intensity is slightly up because CNG vehicles incur a small fuel economy penalty. Because the fuel supply system has never been carbon constrained, low-cost opportunities for reducing $f$ might exist. Vehicle energy intensity has been constrained for some time by fuel economy regulation, likely exploiting low-cost opportunities to reduce $e$. One might expect economically balanced vectors to fall in the third quadrant relative to the $(1,1)$ point, in that it would seem surprising if incrementally reducing $f$ is much more costly than incrementally reducing $e$. This conjecture is not based on formal economic analysis, but illustrates a question raised when examining vehicle-fuel systems from this perspective.

This plot underscores how the GHG impact of any AFV option ultimately depends on the fuel system, a conclusion reached by conventional scenario analyses (e.g., McCollum \& Yang 2009; Sutherland 2010; Melaina \& Webster 2011). The challenge is illustrated for electric cars, which are roughly three times as fuel efficient as conventional, non-hybrid gasoline cars. Per unit of delivered energy, however, the U.S. electric grid is on average about twice as carbon intensive as gasoline. ${ }^{8}$ BEV GHG emissions work out to $40 \%$ lower than a comparable gasoline car's for the contemporary example plotted in Figure 1. For a BEV fleet to achieve an $80 \%$ emissions reduction, the U.S. electric power system would have to be about $85 \%$ less carbon intensive than it was in 2005. A parametric analysis by Barter et al. (2012) also identified the challenges of achieving large GHG reductions with BEVs in comparison to improved efficiency gasoline vehicles. 


\section{Analysis}

The normalized approach just introduced enables exploration of the trade-offs among factors involved in limiting auto sector GHG emissions. To select values for analysis, it is useful to review recent trends and projections.

\subsection{Factor Trends}

Current sector emissions levels are a product of how the underlying factors have evolved to date. Growth in automobile energy use and GHG emissions is driven by travel demand, which in turn reflects rising population and affluence as mediated by the economic and geographic factors that shape transportation in a given region.

Figure 2 shows total U.S. VMT (including heavy trucks and buses) since 1936 and automobile (LDV) VMT since 1966 (FHWA 2011 and prior editions). As of 2005, total travel was 3.0 trillion miles and automobile travel was 2.7 trillion miles $\left(4.3 \times 10^{12} \mathrm{~km}\right)$. Thus, cars comprise about $90 \%$ of total U.S. road travel. An exponential fit to VMT since 1936 yields a compound rate of $3.7 \%$ per year. After about 1990, growth slows and

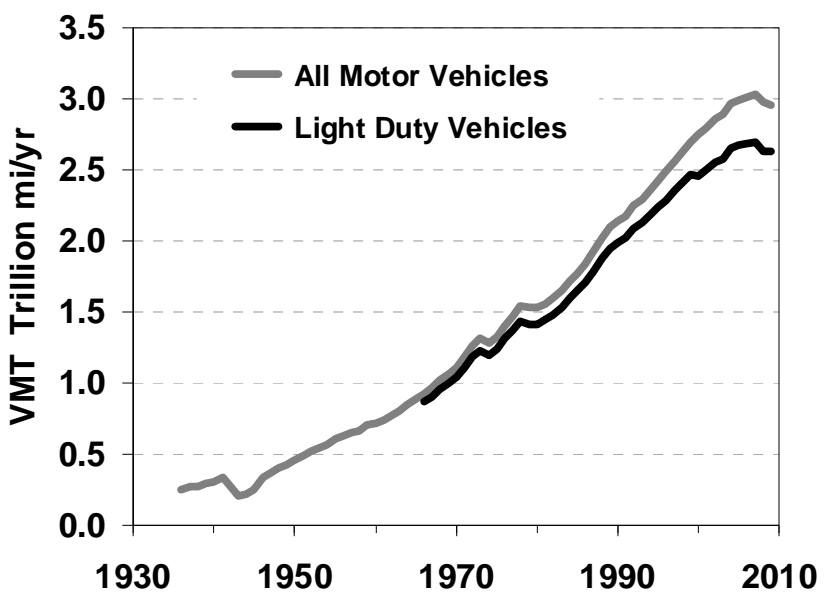

Figure 2. Vehicle miles of travel (VMT) in the United States, 1936-2010

Source: FHWA (2011) recent data show smaller increases. The decline is more pronounced than explained by the economic slowdown, suggesting a saturation in car travel and portending slower growth in the future (Puentes \& Tomer 2008; Millard-Ball \& Schipper 2011).

Automobile energy intensity is also affected by affluence, but it does not have the strong tie seen for travel activity. It depends on the state of automotive technology and to what ends (customer amenities) technology is applied (An \& DeCicco 2007). For the U.S. on-road vehicle stock, FHWA (2011 and prior editions) provides a long-running fuel economy series derived from VMT and fuel volumes as estimated from tax receipts. For new LDVs since 1975, EPA (2012) publishes a detailed series based on laboratory tests. Figure 3 plots energy intensity values derived from both series, illustrating how the on-road stock lags the new fleet due to stock turnover. 
Given the auto sector's reliance on petroleum, fuel-related GHG emissions have varied little. For traditional motor fuels, the fuel system GHG impact has two main components. By far the larger portion is $\mathrm{CO}_{2}$ from end-use fuel combustion, which depends on chemical carbon content though minor variations exist due to incomplete combustion and trace gases. ${ }^{9}$ The other portion is "upstream"

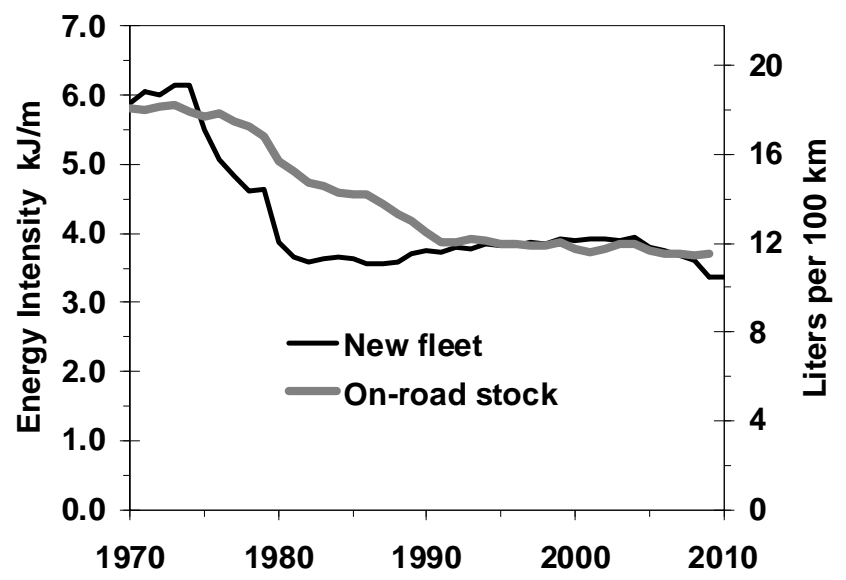

Figure 3. Energy intensity of U.S. automobiles, 1970-2010

Source: derived from EPA (2012), FHWA (2011) emissions during fuel production, including extracting, shipping and refining crude oil and distributing fuel products.

Figure 4 breaks down lifecycle GHG emissions for a typical U.S. gasoline car. ${ }^{10}$ Emissions during vehicle materials production and manufacturing account for about $9 \%$ of the total prorated over a vehicle lifetime. ${ }^{11}$ The great majority (91\%) of emissions are related to fuel use and are largely proportional to the quantity of fuel consumed.

The chemical carbon content, and so direct, end-use $\mathrm{CO}_{2}$ emissions, of motor fuels varies little on an energy basis and is a function of the carbon-to-hydrogen ratio. Carbon content determines the direct, "emissions certain" that occur in the auto sector, as opposed to emissions (and potentially offsetting $\mathrm{CO}_{2}$ uptake by biofuel feedstocks) that occur in other sectors. In the United States and most other OECD countries, the direct emissions are fairly well known because motor fuel consumption is routinely reported and fuel chemistry is readily characterized.

Figure 5 shows trends in direct GHG emissions from gasoline combustion and electricity generation. The scales are consistent in that the electricity units

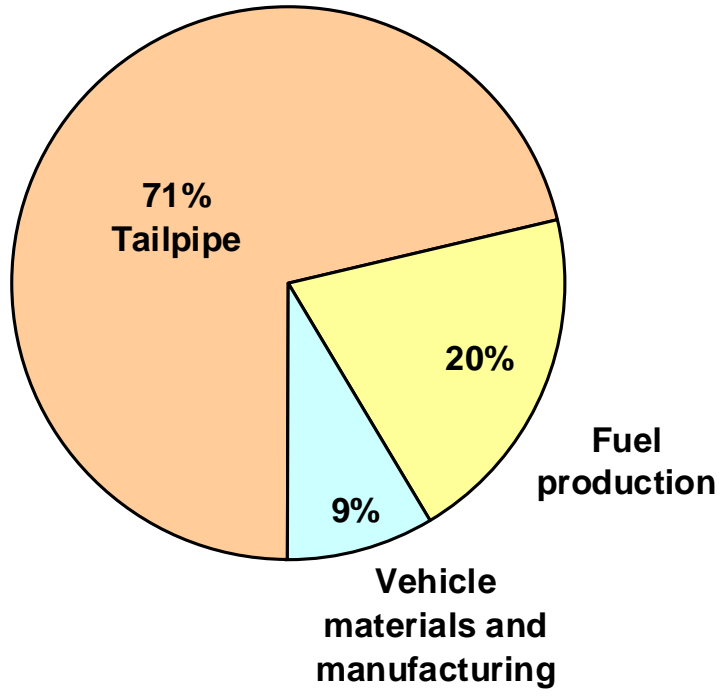

Figure 4. GHG emissions breakdown for a typical U.S. light duty vehicle Source: derived from GREET (2011) 
( $\mathrm{gCO}_{2} / \mathrm{kWh}$ ) equal the gasoline units ( $\mathrm{gCO}_{2} / \mathrm{MJ}$ ) multiplied by a conversion factor (3.6 MJ/kWh); both are national averages. This comparison is not "apples-to-apples" in that it does not use full fuel cycle estimates. For gasoline, it excludes upstream emissions of $\mathrm{CO}_{2}$ and other GHGs; for electricity, it excludes the upstream emissions during coal mining, natural gas processing and the like as well as distribution losses and emissions of other GHGs during all phases of the fuel cycle. Nevertheless, this graph reflects the most certain data for each fuel. It shows a modest declining trend for electricity, reflecting greater use of natural gas and some renewables rather than coal, in contrast to the constancy of direct $\mathrm{CO}_{2}$ intensity for gasoline.

Upstream emissions are not systematically measured and reported, although aggregate estimates are made for GHG inventories. Direct $\mathrm{CO}_{2}$ emissions from U.S. power generation are fairly well known because the sector's energy use is reported in detail. But otherwise, upstream GHG estimates from the industrial processes associated with energy supply suffer from lack of stable, detailed data. In recent editions of its GHG emissions inventory, for example, the U.S. EPA greatly increased estimates of methane emissions from the U.S. oil and gas sector, affecting upstream GHG impact estimates for all fuels including electricity. The implied increases in fuel cycle GHG emissions range from $2 \%$ for electricity to $10 \%$ for CNG. ${ }^{12}$ As GHG reporting requirements are put into place, the quality of data for characterizing upstream emissions should improve. However, to the extent that some upstream processes occur outside U.S. borders, large uncertainties will remain unless international protocols are implemented for tracking productionrelated GHG impacts of traded energy products.

The situation is even more murky for biofuels. Replacing gasoline with ethanol has little appreciable effect on direct (tailpipe) $\mathrm{CO}_{2}$ emissions because ethanol's chemical carbon content differs little from that of gasoline per unit of energy. However, the upstream impacts of any biofuels now produced at commercial scale are too uncertain to meaningfully quantify. 
Traditional lifecycle modelers and government biofuel advocates claim significant GHG emissions reduction benefits (Wang et al. 2011). However, profound uncertainties and ongoing scientific debates surround the extent of net $\mathrm{CO}_{2}$ uptake (Searchinger 2010); the magnitude of associated $\mathrm{N}_{2} \mathrm{O}$ emissions (Crutzen et al. 2008); and the suitability of lifecycle analysis for fuels policy (DeCicco 2012). One leading analyst concludes that "calculating the climate impact of biofuels is so complex, and our understanding is so incomplete, that we can make only general qualitative statements" (Delucchi 2010, p. 28).

Although the GHG impact of biofuels traditionally was presumed to be beneficial relative to fossil fuels because of $\mathrm{CO}_{2}$ uptake in biomass, a more prudent view is that it is scientifically indeterminate. The net effect depends on assumptions about the future biomass regrowth needed to offset the biogenic $\mathrm{CO}_{2}$ released both directly and indirectly when biofuels are produced and combusted, assumptions that are inherently unverifiable. The literature remains far from consensus even on methodology, and it is an issue that confronts the limits of LCA and other methodologies for addressing GHG emissions and associated climate impacts (Delucchi 2011).

\subsection{Future Expectations}

Globally, automobile energy use is projected to grow by a factor of 1.9-2.5 by 2050 (IEA 2009, p. 129). Growth rates vary greatly by region, with high growth in the developing world while the United States and other OECD countries may see little growth and even small declines in some cases. As long as transportation relies on the use of carbon-based fuels without carbon mitigation, $\mathrm{CO}_{2}$ emissions will grow largely in step with energy use, if not indeed a bit faster as unconventional fossil resources come into play. Although ways to produce fuels with lower GHG emissions are being researched, no trend of substantial "decarbonization" is presently apparent for any fuel. This analysis treats the fuel factor $(f)$ as the unknown, with levels implied by the assumed levels of energy intensity $(e)$, travel demand $(d)$ and carbon emissions limit $(c)$.

\subsubsection{Travel demand}

EIA (2011a) projects U.S. light duty VMT growth averaging roughly 1.6\% per year through 2035. Extrapolating to 2050 at that compound rate yields a doubling of VMT relative to the 2005 level. This level was used in Figure 1 and is taken here as a U.S. high-growth case. A lowgrowth case is defined by assuming aggregate travel 20\% lower in 2050, for VMT rising 60\% over 2005-2050 and a average growth rate of about 1\% per year. Such lower growth might happen through some combination of the saturation suggested by recent data and policy changes 
oriented to limiting growth in automobile use, e.g., as discussed by TRB (2009) and Cambridge Systematics (2009).

In non-OECD countries, by comparison, a factor of seven increase in light vehicle passenger travel is projected over 2005-2050 (IEA 2009, p. 211), for an average growth rate of 4.4\% per year. For China, Huo et al. (2012) project growth in automobile travel by a factor of five to eight, as discussed further below. Such extrapolations are of course highly uncertain. Very different solutions for personal mobility might emerge in a developing world that is at once far more populous and much less endowed with oil while being vastly more sophisticated in terms of information technology compared to when the automobile age began a century ago.

\subsubsection{Energy intensity}

Automobile energy intensity is expected to decline due to regulatory pressure overlaying typically higher but still volatile fuel prices. U.S. policymakers have proposed raising fuel economy standards to roughly 50 mpg by 2025 (EPA \& NHTSA 2011). After adjusting for credits and shortfall, that would decrease new fleet average energy intensity from the $3.6 \mathrm{~kJ} / \mathrm{m}$ level of 2005 to $1.9 \mathrm{~kJ} / \mathrm{m}$ in new vehicles by 2025; the on-road stock intensity will lag, of course. Globally, fuel efficiency or vehicle $\mathrm{CO}_{2}$ standards are being promulgated in most major car markets including China. The Global Fuel Economy Initiative is targeting a 50\% reduction in energy intensity for the global on-road automobile stock by 2050 (GFEI 2009).

Engineering studies indicate that over the next 25 years, powertrain advances can reduce light vehicle energy intensity by 65\%-70\% (Kasseris \& Heywood 2007). Although costs are involved, the fuel economy of new U.S. vehicles could be tripled by 2035 (DeCicco 2010). Allowing for turnover, the 2050 on-road stock could have an $e$ value of 0.33 compared to current vehicles. Realizing this potential will depend on a combination of market, social and policy influences. Broadly speaking, the potential for efficiency gain is similar throughout the world because automaking is so globalized. Although the influences are likely to play out differently in different countries, little basis exists for assuming different technical potential, and so this analysis use the same relative energy intensity for the United States and China. These lower energy intensity levels pertain to cars of size and performance similar to today's, still based on liquid fueled internal combustion engine vehicle (ICEV) designs with modest lightweighting and grid-free hybrid drive.

An electric vehicle (EV) that draws power from the grid is inherently more efficient than an ICEV because major energy conversion losses occur at the power plant rather than the car 
engine. EVs have about one-third the energy intensity of current non-hybrid, non-efficiencyoptimized vehicles. Plug-in hybrids (PHEVs) offer energy intensity levels between those of pure EVs and ICEVs depending on design and mix of driving. In any case, electrification of some portion of the fleet is another path to automobile energy intensity levels one-third of today's. ${ }^{13}$ Further reduction is possible if the fleet mix becomes smaller or if performance (such as load hauling ability) is reduced, as seen in many urban EV designs.

An even greater reduction might be seen if autonomous (self-driving) vehicles emerge. Extensive research is underway on this topic and the range of possibilities is immense. At one end of the spectrum are robot cars of full size and performance, such as the sport-utility vehicles used in autonomous driving competitions (Gibbs 2006) and conventional cars used in a Google project (Markoff 2010). At the other end of the spectrum are small, one- or two-person podcars such as the MIT Media Lab's CityCar and similar concepts (Mitchell et al. 2010). For full-size vehicles, efficiencies from automated operation and a balancing of performance capabilities might offer modest additional reductions of energy intensity. More dramatic reductions could be seen with small podcars, which could have a fuel economy 10-15 higher than today's cars (Mitchell et al. 2010, p. 177), implying levels of 0.07-0.1 for relative energy intensity. Although not analyzed here, such disruptive technology changes could have a large impact on emissions if not also accompanied by large increases in vehicle ownership and use.

\subsection{Normalized Scenarios}

The constraints on GHG emissions implied by climate science are uncertain but suggest a need to limit global anthropogenic emissions to about half or less of the 2000 level by 2050 . Assessments of the limits needed to avoid dangerous warming levels indicate that annual GHG emissions might be able to peak in a 2020-30 time frame if they then decline rapidly to 20\%60\% of the 2000 levels by 2050 (van Vuuren \& Riahi 2011). Climate policies depend on domestic and international political considerations as well as the mitigation needs implied by climate science. For the United States, targets on the order of an 80\% reduction below recent levels by 2050 were proposed when climate legislation was considered during Congressional cycles prior to 2010. For China, a 50\% reduction of GHG emissions by 2050 can be examined, mindful that the country's leadership prefers to not use targets when discussing the climate issue.

National and international GHG emission limitation goals are usually defined on an economy-wide basis, not necessarily assuming that all sectors reduce proportionately. It is difficult to allocate emissions among sectors a priori in light of the uncertainties involved. In any 


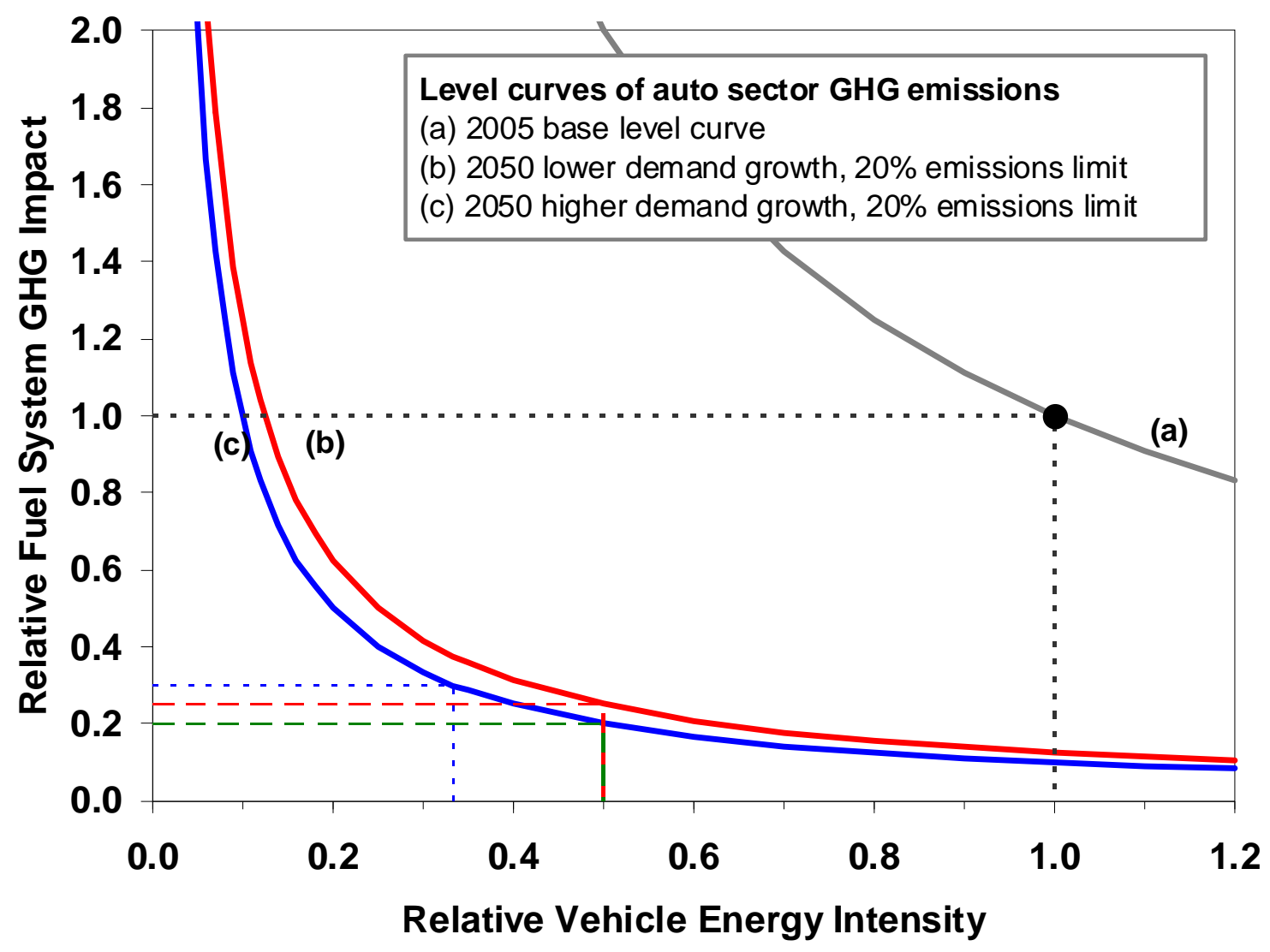

Figure 6. Normalized factor analysis for U.S. auto sector GHG emissions limits for various levels of travel demand growth and vehicle efficiency

case, achieving deep reductions overall is likely to require substantial reductions in all sectors. For purposes of analysis, auto sector reduction targets similar to national-level discussion targets of $80 \%$ and $50 \%$ for the U.S. and China, respectively, are adopted here.

\subsubsection{United States}

A normalized plot of U.S. auto sector GHG emissions is given in Figure 6. Two levels of travel demand growth are illustrated: a higher case of doubling VMT $(d=2.0)$ previously shown in Figure 1 and a lower case $(d=1.6)$ as described above. The implied levels of relative fuel system GHG impact $(f)$ needed for a 80\% GHG reduction $(c=0.20)$ are mapped for two levels of vehicle energy intensity, corresponding to a doubling or tripling of on-road fleet fuel economy. These levels are shown as the green (long dash, $e=0.50$ ) and blue (short dash, $e=0.33$ ) lines in the lower corner of the figure.

For the case of halving energy intensity and doubling VMT, the result is quite simple: 


$$
f=c / d e=(0.20) /[(2.0)(0.5)]=0.20
$$

Thus, the level needed for fuel system carbon balance is exactly the same as the level targeted for limiting sector GHG emissions overall. In other words, if an $80 \%$ reduction of auto sector GHG emissions is desired, then an $80 \%$ reduction is needed for the net GHG emissions impact of the fuel system that supplies the sector.

As shown by the $e=0.33$ line, tripling fleet efficiency against a doubling of demand growth still requires a substantial reduction in fuel system carbon balance, to $f=30 \%$ of the current level, i.e., a 70\% reduction. Even with low VMT growth a major reduction in is still needed; in that case, $d=1.6$ instead of 2.0 , and so

$$
f=(0.20) /[(1.6)(0.5)]=0.25
$$

Thus, trimming VMT growth by 25\% only changes the degree of fuel system GHG reduction needed from $80 \%$ to $75 \%$, as illustrated by the slightly higher (red) long dash line in Figure 6. While the particular values change, the general conclusion is that a stringent limit for total auto sector GHG emissions requires a limit of similar stringency for fuel system GHG impact. Of course, a higher level of fuel economy with lower travel demand would relax the constraints on the fuel system, e.g., to $f=0.38$ (not shown), or $62 \%$ below its current level, but that still entails a major GHG impact reduction.

\subsubsection{China}

In contrast to the U.S. situation, China's auto sector is growing rapidly, though projections are quite uncertain. Huo et al. (2012) developed a model for vehicle use in China based on surveys of current usage, travel by vehicle age in China and elsewhere and historical relationships of vehicle travel to per capita GDP. Even the current amount of driving in China is poorly known; a modeled midrange estimate is roughly one trillion vehicle kilometers of travel (VKT), i.e., $1 \times 10^{12} \mathrm{~km}$ per year in 2010 . Recent growth rates appear to be in the range of $8 \%-18 \%$ per year and the model projects that travel demand in China may reach 4.8-8.0 trillion km by 2050 (Huo et al. 2012). This implies a $d$ factor of 5-8, a range consistent with the factor of 7 growth in nonOECD travel demand foreseen by IEA (2009).

Figure 7 plots the level curves for achieving a 50\% GHG emissions reduction $(c=0.50)$ for China's auto sector in the face of such growth. Real-world fleet average vehicle energy intensity levels in developing countries are also highly uncertain as is the future evolution of vehicle fleets. Given the globalized nature of the automobile market, however, it is reasonable to 


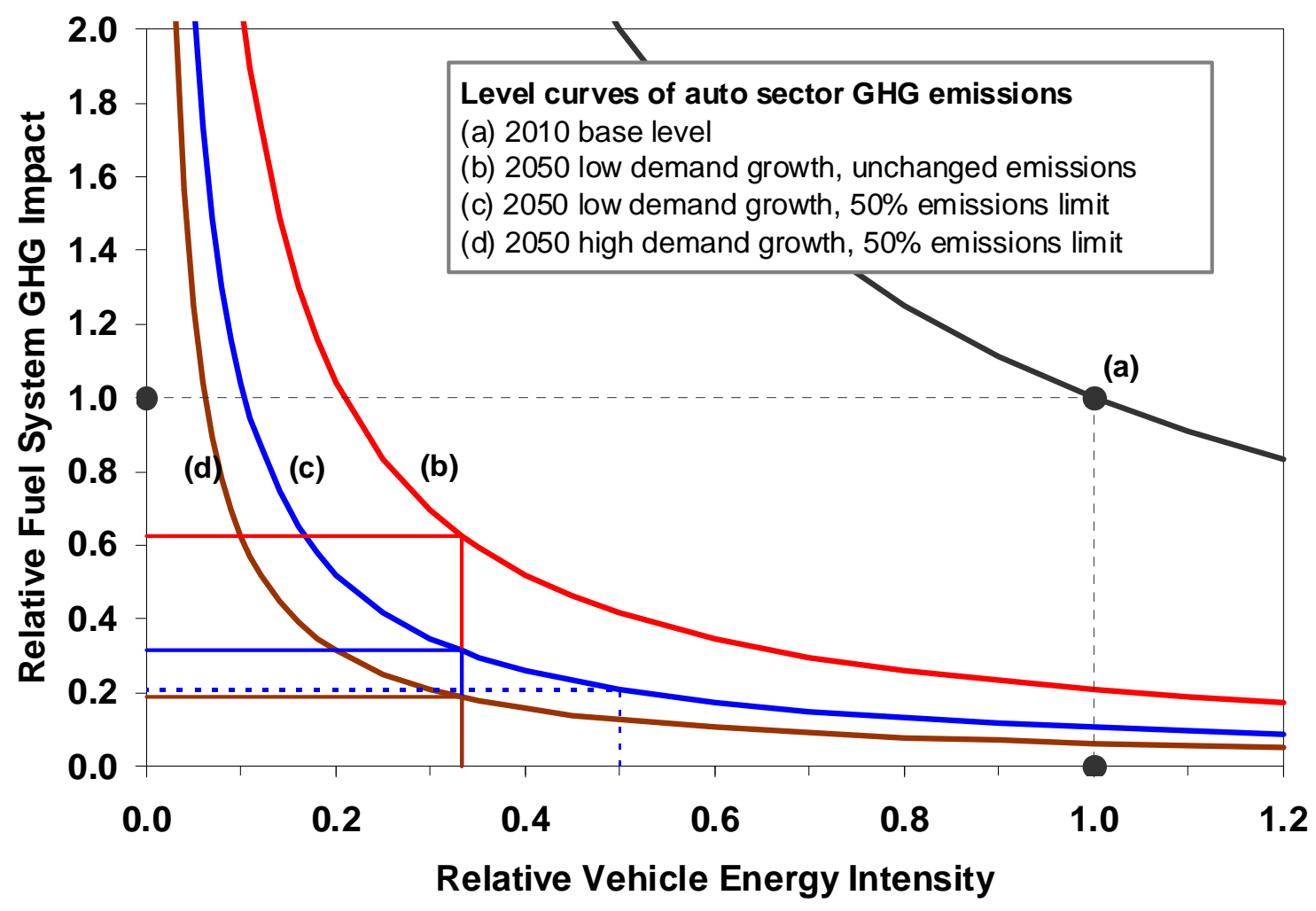

Figure 7. Normalized factor analysis for China auto sector GHG emissions limits for various levels of travel demand growth and vehicle efficiency

assume relative efficiency gains similar to those elsewhere, i.e., a doubling to tripling of fleet average fuel economy, or $e$ levels of 0.5 and 0.33 .

The normalized fuel system GHG impact implied for tripled vehicle efficiency is mapped for three combinations of the $c$ and $d$ factors using the solid lines in Figure 7. To avoid cluttering the graph, only one case is mapped for doubled vehicle efficiency. For a tripling of vehicle efficiency and limiting GHG emissions from China's auto sector to $50 \%$ of current levels by 2050, the low to high range of travel demand growth implies a fuel system carbon balance level of 0.3 to 0.2 ( $70 \%$ to $80 \%$ reduction), respectively, relative to the current fuel system. A doubling of vehicle efficiency and low demand growth implies an $f$ factor of 0.21 , also in this range, which is quite similar to that implied for U.S. conditions and an 80\% GHG reduction target. If instead the target is limiting 2050 emissions to current levels, i.e., no net growth in China auto sector GHG emissions over this 40 year horizon, then curve (b) in Figure 7 shows that tripled vehicle efficiency implies a fuel system carbon balance factor of roughly 0.6 , or a $40 \%$ reduction in fuel system normalized impact. 
China's electricity supply is heavily coal dependent, ranging from roughly $65 \%$ in the south to $98 \%$ coal in the north (including the Beijing region) and implying a fuel GHG intensity factor ( $f$ ) of about 2.5 relative to gasoline (derived from Huo et al. 2010). An EV in China today falls above the chart in Figure 7 and, even with its higher fuel efficiency than a gasoline car, offers little GHG benefit relative to -- and in some regions is worse than -- a comparable gasoline vehicle (Huo et al. 2010). Compared to the GHG reduction needed for liquid fuels used in highefficiency engines, a greater percent reduction of power sector GHG emissions rates is needed to limit EV emissions to a given level. Thus, the prior finding for the United States is even stronger for China due to its carbon intensive power sector.

\section{Discussion}

This analysis underscores the importance of limiting net GHG emissions of the fuel supply system, an inference that is not necessarily inconsistent with the traditional promotion of alternative fuels for climate policy. However, it highlights two points: (1) the use of alternative fuels per se does not limit GHG emissions from their supply systems; and (2) addressing fuel system GHG impacts does not necessitate alternative fuels, i.e., different end-use energy carriers for vehicles. Point (1) is self-evident. For point (2), a counterexample is the set of options for balancing the $\mathrm{CO}_{2}$ emissions from end-use combustion of hydrocarbon fuels with $\mathrm{CO}_{2}$ uptake in the fuel supply system (as for drop-in biofuels) or with sequestration at other locations upstream from fuel supply (e.g., $\mathrm{CO}_{2}$ enhanced oil recovery).

Policy discussions can become confused when imprecise use of language conflates a fuel (energy carrier) with the system that supplies it. For example, the term "low-carbon fuel" is used as shorthand for "fuel produced and used with low net GHG emissions impact." Greater clarity exists if the word fuel, or the name of a fuel, is used precisely to refer to a physical energy carrier, and not used when what is really meant is an entire supply system. These points are elaborated further below. Although for simplicity of exposition the fuel factor $(f)$ is plotted here unidimensionally on an axis labeled "fuel system GHG impact" (often called carbon intensity), it should be understood as an emergent impact of a complex and dynamic supply system. Its effects are located in other sectors and may cross international borders; the associated GHG fluxes can have time-varying components and involve induced effects that respect neither spatial nor temporal boundaries. Examples include the time-dependent radiative forcing of methane, impacts 
on the biosphere's carbon stocks, and commodity market interactions for both fossil and renewable feedstocks; none of these effects are trivial.

The complications surrounding fuel system GHG impacts have become apparent as the carbon intensity metric has moved from the arena of academic analysis to regulatory policy, as seen in the lifecycle GHG emissions thresholds of a low-carbon fuel standard (LCFS) or a renewable fuel standard (RFS). Problems identified in recent studies include: verifying carbon intensity through complex energy distribution systems is difficult for many fuels including electricity (Andress et al. 2010); quantification of key impacts through LCA is overwhelmed by uncertainties (Plevin et al. 2010); and available analytic tools are inadequate for providing reliable results (Delucchi 2011).

\subsection{Focusing on the location of emissions}

These problems arise when developing policies that target fuel choice; they can be avoided by realizing that fuel-related GHG emissions are best addressed by policies that target the locations where GHG impacts actually occur. Though obvious when so stated, this precept is obscured in discussions that invoke LCA to reduce complex system impacts to a "carbon footprint" that is then treated as if it were a fuel property. Such thinking fosters a misguided emphasis on changing the motor fuel rather than managing carbon and greenhouse gases in the associated energy and natural resource sectors.

Further clarity can be found by making another distinction, that of a source-focused analytic framework from a product-focused framework. A fuel is a product and analyzing it or the system that produces it involves product-focused analysis, that is, an analysis with system boundaries defined by what is deemed relevant to the production and use of the fuel. LCA is an tool for analyzing product systems and so LCA-based policies such as an LCFS are productfocused. In contrast, a source is simply a specific entity from which GHGs are emitted, and so a source-based approach focuses on the locations where emissions occur. A car burning a carbonaceous fuel is a source, as is a refinery, a power plant, a farm or forest (which can be a negative source, i.e., a sink).

Source-based accounting is generally used for official GHG inventories. Emissions are tallied by the sectors from which $\mathrm{CO}_{2}$ or other gases are directly emitted, and $\mathrm{CO}_{2}$ sinks are similarly tallied. A purely source-based framework would count $\mathrm{CO}_{2}$ uptake in biomass growth (in the agricultural or forestry sectors) separately from $\mathrm{CO}_{2}$ emissions from biofuel combustion 
(in the transportation sector) even though these separate locations may be connected by a supply chain.

Climate policy to date is not purely source-based because it omits biogenic $\mathrm{CO}_{2}$ from energy sector inventories under an assumption that it is negated by $\mathrm{CO}_{2}$ uptake elsewhere and that any associated carbon stock changes are properly tallied in land-use sectors. This productbased LCA convention encroaches into what would otherwise be a source-based method. Although arithmetically correct, it is an accounting shortcut that sets up a misplaced burden of proof regarding emissions and uptake (DeCicco 2012). Searchinger et al. (2009) recommend counting all $\mathrm{CO}_{2}$ emissions where they occur regardless of the origin of the energy product and addressing bioenergy under rules for carbon offsets, attentive to whether any claimed $\mathrm{CO}_{2}$ uptake is truly additional.

\subsection{Implications of a source-based framework}

Broadly speaking, the net GHG emissions impact of transportation fuel use can be addressed in three ways:

(1) Use physically carbon-free fuels, such as electricity or hydrogen, that avoid the release of $\mathrm{CO}_{2}$ from vehicles themselves. ${ }^{14}$ This requires low GHG fuel production systems and therefore policies directed at GHG emissions in the electric power sector and other related energy and industrial sectors.

(2) Use carbon-based fuels and counterbalance their end-use $\mathrm{CO}_{2}$ emissions with sufficient net $\mathrm{CO}_{2}$ uptake elsewhere. Ensuring verifiable net uptake also requires policies focused outside the transportation sector, such as measures to address GHG emissions in the agriculture, forestry, biorefining and related industrial sectors involved in biofuel production.

(3) Prevent the release of $\mathrm{CO}_{2}$ from combustion or other utilization of carbon-based fuels in vehicles, e.g., by using hydrocarbons with onboard $\mathrm{CO}_{2}$ capture or using only the hydrogen and separating the carbon for removal. Such options face very adverse thermodynamics and practical ways to implement them are not known.

Therefore, for the known feasible options (1) and (2), GHG emissions related to the transportation sector cannot be adequately controlled absent efforts to control GHG in other sectors, namely, those that produce fuel.

Carbon-based liquids are by far the dominant motor fuels because of their energy density and ease of distribution. As noted earlier, these same traits make them fungible commodities. 
They therefore pose special challenges because emissions fluxes tied to their production cannot be readily and verifiably tracked through their dynamic supply chains. These issues confound attempts to estimate the climate impacts of biofuels, because biomass feedstocks interact in significant but not directly traceable ways through commodity markets that impact land use.

Because the atmosphere is indifferent to the location of $\mathrm{CO}_{2}$ emissions, it makes no difference whether fossil-derived $\mathrm{CO}_{2}$ from fuel use is offset by a sink or sequestration elsewhere or whether the fuel carbon came from $\mathrm{CO}_{2}$ absorbed when growing biomass. What matters is whether the $\mathrm{CO}_{2}$ uptake is verifiably additional on a global basis (Searchinger 2010). The claimed benefit for any form of bioenergy hinges on the removal of $\mathrm{CO}_{2}$ from the atmosphere by photosynthesis. Photosynthesis is a resource intensive process, requiring land, water and nutrients, particularly if high productivity is desired. If there is an additional net removal of $\mathrm{CO}_{2}$ from the air and fixation in biomass, it likely will involve a significant resource cost. From a climate perspective, why not stop right there? Though not so stated, such a question is also implied by Righelato \& Spracklen (2007).

Marland \& Marland (1992) investigated similar issues for forests and found that the answer depends on the initial quality of forest carbon stock, expected growth rates, harvest and biofuel conversion efficiencies and the time horizon. They also noted that atmospheric impacts are the same whether harvested biomass is used to displace fossil fuels or is sequestered, e.g., in long-lived forest products. Many other studies have highlighted the complexities of bioenergy. These issues cannot be fully resolved through product-focused LCA and ultimately will require source-focused GHG accounting (DeCicco 2012). Carbon sequestration or offsets may be more effective ways to reduce the net GHG impact of liquid fuels than biofuels obtained from commodity supply chains that interact in untraceable ways with the biosphere's carbon cycle. Thus, a source-based approach can expand the auto sector solution set beyond the traditional options based on seeking GHG reductions through alternative fuels. An implied research need is assessment and development of robust and verifiable ways to explicitly counterbalance the $\mathrm{CO}_{2}$ directly released by the combustion of liquid fuels.

\subsection{Questioning the case for AFVs}

Building on the distinctions made above, greater scrutiny can be given to the arguments used to advocate public policies for deploying AFVs. It is common to present scenario analyses showing how AFVs can greatly reduce emissions. Such scenarios rest on many assumptions about how the envisioned vehicle-fuel systems will develop in the future and, just as importantly, many 
assumptions (often unstated or even unrecognized) about how other systems will not develop. For example, it is often assumed that the net $\mathrm{CO}_{2}$ impact of petroleum use cannot be greatly changed, or that geological or enhanced biological carbon sequestration cannot be developed at scales sufficient to counterbalance $\mathrm{CO}_{2}$ emissions from motor fuel consumption. While AFV scenario analysis may be partly data driven, it is never completely so and indeed cannot be because it pertains to how technologies and markets develop in the future.

Analysis to justify the pursuit of AFV concepts is useful for guiding research, which requires choosing promising options for an $\mathrm{R} \& \mathrm{D}$ portfolio. It is common to work backward from predictions of future success for the chosen systems to set R\&D targets, for example. However, such analyses are a weak foundation for arguments on behalf of policies that go beyond R\&D, for example, the use of technology-based mandates or incentives, and seek to push AFVs into the marketplace. Those strategies also have a poor track record; several decades of supportive policy have failed to make AFVs commercially viable at meaningful scales or to deliver significant environmental benefits (McNutt \& Rodgers 2004). The empirical evidence provided by that history should raise questions about the premises of AFV programs.

Another common rationale for policies to deploy AFVs is urgency. Developing new technologies and supporting infrastructures takes years of lead time, confronts many barriers and faces high transition costs (Singh \& Mintz 1997). Thus, the argument goes, it is essential to "get started now," i.e., for policymakers to initiate efforts to commercialize AFVs well before private actors would make such investments on their own. However, a different view follows from the factor analysis presented here, which clarifies the importance of focusing on the GHG impact of the energy sectors supplying fuel. The true urgent need is control of emissions in energy sectors. Success in that endeavor is prerequisite for AFVs to have significant climate benefits and is also consistent with the need for measures that target GHG sources and sinks in situ.

Because automobile stock turnover is more rapid than capital stock turnover in energy sectors, the value of a shift to particular AFVs may become clear if particular energy sectors progress more rapidly than others in limiting net GHG emissions. Such progress is not yet apparent in the United States, where none of the energy sectors yet face significant GHG constraints. Inadequate regard for not only the long time frames involved in energy supply infrastructure, but also the extensive, systemic changes required, is a liability for AFV strategies rationalized by the shorter product cycles of automaking. Critically examining the case of hydrogen and fuel cell vehicles, for example, Eisler (2012) points out how such challenges can 
be masked by the tangibility of vehicle technology demonstrations. The implication is not that AFVs will never be needed, but rather that any particular need for them cannot be resolved at present. Lessons may be learned in California, which has an electric power system less carbon intensive than average and is implementing a cap-and-trade program. Nevertheless, the extent to which California's strategies will be scalable nationally and internationally is unclear.

This analysis is based only on climate considerations, not on the energy security and economic rationales for replacing petroleum that predate policy concern for climate. Presumptive support of AFVs for climate mitigation can be seen as an extension of their longtime support for other reasons. This paper's analysis reveals how climate policy might deviate from the accepted approaches of energy policy. Because efforts to foster market adoption of AFVs are rationalized by tautology if petroleum displacement is the goal, a finding that AFV promotion per se is unhelpful for climate is a clear point of difference. Otherwise put, this analysis implies that efforts to deeply reduce auto-related GHG emissions need not be held hostage to AFV strategies and their associated transition barriers, such as infrastructure needs, cost hurdles and consumer acceptance challenges.

\section{Conclusion}

Cars count among the major challenges of limiting global GHG emissions to minimize climatic risk. The three broad approaches for controlling emissions -- travel demand reduction, vehicle efficiency and alternative fuels -- are commonly analyzed by factoring total sector GHG emissions into travel distance, fuel intensity per distance of travel and carbon intensity of fuel. Though typically used for technology-oriented scenario analysis, this decomposition enables a more fundamental examination of the issue, independent of particular technology options.

A normalized factor analysis method underscores the importance of deeply reducing the net GHG emissions from fuel supply systems, regardless of the fuel considered and even with large gains in vehicle efficiency. For a broad range of conditions, any stringent emissions limit for the auto sector implies a need to limit the emissions of associated energy supply sectors with a comparable degree of stringency. Otherwise put, for the fuel aspects of GHG emissions control, treating the "vehicle and fuel as a system" requires an upstream focus on emissions in fuel supply systems rather than a downstream focus on the quality or form of fuel products, in contrast to what has been the paradigm for conventional mobile source air pollution control. 
The critical importance of fuel system GHG impact invites careful consideration of just what this factor means. Most analyses to date treat it in terms of carbon intensity as computed by lifecycle analysis (LCA). However, carbon intensity is an abstraction based on modeling that is highly imperfect and in some cases scientifically indeterminate. Lifecycle carbon intensity is not directly measurable and cannot be treated as if it were an observable property of a fuel. The GHG impacts of concern that motivate LCA occur at sources and sinks remote from the point of fuel use itself. The only scientific way to address these impacts is through measurement and management of GHG emissions and net $\mathrm{CO}_{2}$ uptake in the locations where they actually occur.

Clarifying that it is not the fuel (i.e., end-use energy carrier) that matters, but rather the systems that produce it, implies a different emphasis, namely, on addressing GHG sources and sinks in fuel supply sectors rather than on fuel choice in the transportation sector. This is true whether the fuel is literally carbon-free (electricity or hydrogen) or is chemically carbon-based (hydrocarbon or alcohol). The extent to which a shift from carbon-based to carbon-free motor fuel is needed then reduces to an economic question, rather than being scientifically necessary for climate protection. The role of biofuels similarly reduces to an economic question, pertaining not only to the cost of synthesizing biofuels compared to fossil fuel products, but also -- and most importantly -- to the cost of achieving net $\mathrm{CO}_{2}$ uptake in the biosphere.

Therefore, in addition to travel demand reduction and vehicle efficiency, the "third leg" of auto sector climate policy should be reducing the net GHG impact of fuel supply sectors. Given the overwhelming dominance of liquid hydrocarbons, the most timely steps will entail GHG management for the petroleum sector. Because liquid fuels, crude oils and other feedstocks are fungible, globally traded commodities produced by dynamic supply chains, developing appropriate GHG tracking protocols and policies to manage and offset the large flows of carbon through this system is an important research need. While it may be informative at a general level, LCA is unsuited for this type of environmental management task.

A final implication is that, beyond fundamental R\&D in hope of breakthroughs, policies to promote AFVs are not currently warranted for climate protection. Though they may become useful someday, which alternatives will be needed and when cannot be ascertained today. The question of whether promoting AFVs for energy security and trying to replace petroleum rather than manage its risks are worthwhile endeavors is not addressed here. What is clear is that auto sector GHG emissions cannot be adequately limited without concerted efforts to limit GHG emissions from the sectors that supply motor fuel, whatever form that fuel may take. 


\section{ACKNOWLEDGEMENTS}

This work was supported in part by the Clean Energy Research Center Clean Vehicle

Consortium (CERC-CVC) under U.S. Department of Energy award DE-PI0000012. The author

is also grateful to several colleagues and anonymous reviewers who provided comments and

suggestions on drafts of this analysis. The statements and opinions expressed herein do not

necessarily reflect those of the U.S. government or any agency thereof, and the author retains

sole responsibility for the analysis and conclusions.

\section{ENDNOTES}

${ }^{1}$ EPA (2012) gives new light duty average on-road fuel economy estimates of 19.9 mpg for model year 2005 and $22.6 \mathrm{mpg}$ for model year 2010. Such on-road fuel economy estimates reflect an average shortfall of $20 \%$ compared to the lab test values used for CAFE compliance. The 2010 point also reflects a slight (1\%) increase in gasoline GHG intensity based on comparing an estimate of $91.8 \mathrm{gCO}_{2} \mathrm{e} / \mathrm{MJ}$ for 2005 (derived from GREET version 1.8c) to an estimate of $92.8 \mathrm{gCO}_{2} \mathrm{e} / \mathrm{MJ}$ for 2010 (derived from GREET 1-2011). For all of the other vehicles shown in Figure 1 and described in the notes below, the efficiency is plotted as efficiency relative to a similarly sized conventional vehicle.

2 The DSL point reflects the relative efficiency of the VW Jetta TDI compared to the Jetta gasoline version, and uses a diesel GHG intensity of 94.4 gCO $_{2} \mathrm{e} / \mathrm{MJ}$ for 2010 (derived from GREET 1-2011).

3 The contemporary HEV point reflects the relative efficiency gain seen in the Toyota Prius, which has an EPAestimated on-road fuel economy of 50 mpg implying an energy intensity of $1.51 \mathrm{~kJ} / \mathrm{m}$, compared to an average midsize car that achieves $27 \mathrm{mpg}$.

${ }^{4}$ The BEV point reflects the relative efficiency gain seen in the Nissan Leaf, which has an EPA rated electricity use rate of $0.34 \mathrm{kWh} / \mathrm{mile}$ (energy intensity of $0.76 \mathrm{~kJ} / \mathrm{m}$ ) and a U.S. average electricity GHG intensity estimate of $685 \mathrm{gCO}_{2} / \mathrm{kWh}$, derived from EIA (2011b), EPA (2010), and GREET (2011).

5 The FCV point reflects the relative efficiency gain seen in the Honda Clarity, which has an EPA rated fuel economy of 59 mpg gasoline-equivalent, and estimated GHG intensity of hydrogen derived from natural gas of $125 \mathrm{gCO}_{2} \mathrm{e} / \mathrm{MJ}$ based on GREET (2011).

6 The CNG point reflects the relative efficiency of the Honda Civic GX and a natural gas system GHG intensity of $80 \mathrm{gCO}_{2} \mathrm{e} / \mathrm{MJ}$ based on GREET (2011).

${ }^{7}$ For compressed natural gas (CNG) vehicles, an important caveat is that the GHG intensity computed by GREET follows the common convention of 100 -year global warming potentials for methane $\left(\mathrm{CH}_{4}, \mathrm{GWP}=25\right)$. However, methane has a much higher short-term radiative forcing (decaying over the very long term to $\mathrm{CO}_{2}$ ). Significant methane leakage is involved in current natural gas supply and distribution, and control is unlikely to become easier with widespread use of CNG vehicles. Analysis of radiative forcing effects finds that CNG vehicles are unlikely to be beneficial for climate over near- or mid-term time horizons and that focus is better placed on addressing methane leakage in natural gas supply systems (Alvarez et al. 2012), a finding consistent with this paper's suggested policy focus on controlling energy sector GHG emissions rather than fuel switching in the automotive sector.

${ }^{8}$ Electric power generation exhibits considerable regional variation. Based on the eGrid database (EPA 2010), direct $\mathrm{CO}_{2}$ emissions for California's power mix are about half the U.S. average while some other regions, such as parts of the Midwest and Rocky Mountain west, rely heavily on coal and have $\mathrm{CO}_{2}$ emission rates nearly $50 \%$ higher than the national average.

${ }^{9} \mathrm{CO}_{2}$ accounts for about $97 \%$ of tailpipe GHG emissions from recent gasoline vehicles; $\mathrm{N}_{2} \mathrm{O}$ accounts for most of the remaining 3\% (Vicuna 2004, Table 1); this estimate is in terms of $\mathrm{CO}_{2}$-equivalency based on a global warming potential of 298 for $\mathrm{N}_{2} \mathrm{O}$. Recent U.S. GHG regulations for vehicles are expected to significantly reduce such trace 


\section{ENDNOTES}

gas emissions, as well as HFC emissions from automobile air conditioners, so that $\mathrm{CO}_{2}$ will come to account for even closer to $100 \%$ of the GHG emitted directly by vehicles that burn carbon-based fuels.

${ }^{10}$ This breakdown is based on 20 mpg in-use fuel economy, 180,000 miles lifetime travel and lifecycle GHG emissions estimates from GREET (2011).

${ }^{11}$ Author's calculations based on fuel cycle emissions factors from GREET (2011) updated using data from EPA (2011) and assuming a vehicle lifetime of 180,000 miles, which is consistent with the U.S. vehicle lifetimes documented by NHTSA (2006).

${ }^{12}$ Author's calculations based on adjusting GREET 1.8d values with methane leakage estimates from EPA (2011); note that these impact estimates assume 100-year GWP values; greater impact estimates would result if examining radiative forcing over a few decades or through mid-century.

${ }^{13}$ Because electrification shifts major energy conversion losses from the vehicle to the power sector, little additional energy intensity reduction is foreseen for EVs of a given size and utility.

${ }^{14}$ Other energetic, non-carbon based chemicals, such as ammonia $\left(\mathrm{NH}_{3}\right)$, hydrazine $\left(\mathrm{N}_{2} \mathrm{H}_{4}\right)$ and their hydrates have been discussed as transportation fuels (and have seen limited use in spacecraft, jet propulsion and fuels cells), but raise issues beyond the scope of this paper.

\section{References}

Alvarez, R., et al. 2012. Greater focus needed on methane leakage from natural gas infrastructure. Proc. Nat. Acad. Sci. 109(17): 6435-40. http://www.pnas.org/content/109/17/6435

An, F. 2010. Low-Carbon Fuels and Vehicle Efficiency Policies in World's New Number 1 Auto Market, China. Transportation Research Board Annual Meeting, Washington, DC, January 11.

An, F., and J. DeCicco. 2007. Trends in technical efficiency trade-offs for the U.S. light vehicle fleet. SAE Paper No. 2007-01-1325. SAE Transactions, Journal of Engines 116: 859-873.

Andress, D., T.D. Nguyen and S. Das. 2010. Low-carbon fuel standard: status and analytic issues. Energy Policy 38: 580-591.

Barter, G.E., et al. 2012. Parametric analysis of technology and policy tradeoffs for conventional and electric light-duty vehicles. Energy Policy 46: 473-88. http://dx.doi.org/10.1016/j.enpol.2012.04.013

Cambridge Systematics, Inc. 2009. Moving Cooler: An Analysis of Transportation Strategies for Reducing Greenhouse Gas Emissions. Washington, DC: Urban Land Institute, July. http://www.movingcooler.info/overview

Chertow, M.R. 2001. The IPAT equation and its variants; changing views of technology and environmental impact. Journal of Industrial Ecology, 4(4): 13-29.

Crutzen, P.J., et al. 2008. $\mathrm{N}_{2} \mathrm{O}$ release from agro-biofuel production negates global warming reduction by replacing fossil fuels. Atmos. Chem. \& Phys. 8: 389-395. www.atmos-chem-phys.net/8/389/2008/

DeCicco, J.M. 2010. A Fuel Efficiency Horizon for U.S. Automobiles. Ann Arbor: University of Michigan, School of Natural Resources and Environment, September. http://hdl.handle.net/2027.42/78178

DeCicco, J.M. 2012. Biofuels and carbon management. Climatic Change 111(3): 627-640. http://dx.doi.org/10.1007/s10584-011-0164-z 
DeCicco, J., and J. Mark. 1998. Meeting the energy and climate challenge for transportation in the United States. Energy Policy 26(5): 395-412.

Delucchi, M.A. 2010. Impacts of biofuels on climate change, land use and water use. Annals of the New York Academy of Sciences 1195: 28-45.

Delucchi, M.A. 2011. Beyond lifecycle analysis: developing a better tool for simulating policy impacts. Chapter 13 of J. Ogden and L. Anderson (eds.), Sustainable Transportation Energy Pathways. Davis, CA: Institute of Transportation Studies, University of California, Davis.

Dunn, J.A. 1998. Driving Forces: The Automobile, Its Enemies and the Politics of Mobility. Washington, DC: Brookings Institution Press.

EIA. 2011a. Annual Energy Outlook 2011. Washington, DC: Energy Information Administration. www.eia.doe.gov/oiaf/aeo/index.html

EIA. 2011b. Electric Power Annual. Washington, DC: Energy Information Administration. www.eia.gov/electricity/annual/

Eisler, M.N. 2012. Overpotential: Fuel Cells, Futurism, and the Making of a Power Panacea. New Brunswick: Rutgers University Press.

EPA. 2007. Inventory of U.S. Greenhouse Gas Emissions and Sinks: 1990-2005. Washington, DC: U.S. Environmental Protection Agency.

EPA. 2010. Emissions \& Generation Resource Integrated Database (eGRID). www.epa.gov/cleanenergy/energy-resources/egrid/index.html

EPA. 2011. Inventory of U.S. Greenhouse Gas Emissions and Sinks: 1990-2009. Washington, DC: U.S. Environmental Protection Agency. www.epa.gov/climatechange/emissions/usinventoryreport.html

EPA. 2012. Light-Duty Automotive Technology, Carbon Dioxide Emissions and Fuel Economy Trends: 1975 through 2011. Washington, DC: U.S. Environmental Protection Agency, Office of Transportation and Air Quality. http://www.epa.gov/otaq/fetrends.htm

EPA \& NHTSA. 2011. 2017 and Later Model Year Light-Duty Vehicle Greenhouse Gas Emissions and Corporate Average Fuel Economy Standards. Notice of Proposed Rulemaking. www.nhtsa.gov/staticfiles/rulemaking/pdf/cafe/2017-25_CAFE_NPRM.pdf

FHWA. 2011. Highway Statistics (annual). Washington, DC: Federal Highway Administration. Table VM-1 series via Vehicle Miles of Travel "Quick Find" webpage, www.fhwa.dot.gov/policyinformation/quickfinddata/qftravel.cfm (accessed 11 June 2011).

GFEI. 2009. 50 by 50: Making Cars 50\% More Fuel Efficient by 2050 Worldwide. London: Global Fuel Economy Initiative. www.globalfueleconomy.org/Documents/Publications/50BY50 report.pdf

Gibbs, W.W. 2006. Innovations from a Robot Rally. Scientific American, January. www.scientificamerican.com/article.cfm?id=innovations-from-a-robot-2006-01\&sc=I100322

GREET. 2011. Greenhouse Gases, Regulated Emissions, and Energy Use in Transportation (GREET) Model. Argonne, IL: Argonne National Laboratory. greet.es.anl.gov/main

Huo, H., Q. Zhang, M.Q. Wang, D.G. Streets and K. He. 2010. Environmental implication of electric vehicles in China. Env. Sci. Tech. 44 (13): 4856-86. dx.doi.org/10.1021/es100520c 
Huo, H., et al. 2012. Vehicle-use intensity in China: current status and future trend. Energy Policy 43: 616. $\underline{\text { dx.doi.org/10.1016/j.enpol.2011.09.019 }}$

IEA. 2009. Transport, Energy and $\mathrm{CO}_{2}$ : Moving Toward Sustainability. Paris: International Energy Agency.

Kasseris, E.P. and J.B. Heywood. 2007. Comparative analysis of automotive powertrain choices for the next 25 years. SAE Paper No. 2007-01-1605. Warrendale, PA: Society of Automotive Engineers.

Markoff, J. 2010. Google Cars Drive Themselves, in Traffic. The New York Times, October 9. www.nytimes.com/2010/10/10/science/10google.html

Marland, G., and S. Marland. 1992. Should we store carbon in trees? Waste, Air, and Soil Pollution 64: 181-195.

McCollum, D., and C. Yang. 2009. Achieving deep reductions in U.S. transport greenhouse gas emissions: Scenario analysis and policy implications. Energy Policy 37(12): 5580-96.

McNutt, B., and D. Rodgers. 2004. Lessons Learned from 15 Years of Alternative Fuels Experience: 1988-2003. Chapter 12 in Sperling, D., and Cannon, J.S. (eds.), The Hydrogen Transition: Moving Toward the Post-Petroleum Age in Transportation. Burlington, MA: Academic Press.

Melaina, M., and K. Webster. 2011. The role of carbon intensity in achieving 2050 greenhouse gas reduction goals within the light-duty vehicle sector. Envir. Sci. \& Tech. 45(9): 3865-71. dx.doi.org/10.1021/es1037707

Millard-Ball, A., and L. Schipper. 2011. Are we reaching peak travel? Trends in passenger transport in eight industrialized countries. Transport Reviews 31(3): 357-378. dx.doi.org/10.1080/01441647.2010.518291

Mitchell, W.J., C.E. Borroni-Bird and L.D. Burns. 2010. Reinventing the Automobile: Personal Urban Mobility for the $21^{\text {st }}$ Century. Cambridge, MA: MIT Press.

NHTSA. 2006. Vehicle Survivability and Travel Mileage Schedules. Report DOT HS 809952. Washington, DC: National Highway Traffic Safety Administration, January.

OTA. 1991. Changing by Degrees: Steps To Reduce Greenhouse Gases. Report OTA-O-482. Washington, DC: U.S. Congress, Office of Technology Assessment.

PDAC. 1996. Policy Dialog Advisory Committee to Assist in the Development of Measures to Significantly Reduce Greenhouse Gas Emissions from Personal Motor Vehicles. Report to the President by Interagency Steering Committee. Washington, DC: National Economic Council.

Plevin, R.J., et al. 2010. Greenhouse gas emissions from biofuels' indirect land use change are uncertain but may be much greater than previously estimated. Environ. Sci. \& Tech. 44(21): 8015-21.

Puentes, R., and A. Tomer. 2008. The Road Less Traveled: An Analysis of Vehicle Miles Traveled Trends in the United States. Metropolitan Policy Program Report. Washington, DC: Brookings.

Raupach, M.R., G. Marland, P. Ciais, C. Le Quéré, J.G. Canadell, G. Klepper and C.B. Field. 2007. Global and regional drivers of accelerating $\mathrm{CO}_{2}$ emissions. Proc. Natl. Acad. Sci.104(24): 10288-293. www.pnas.org/cgi/doi/10.1073/pnas.0700609104

Righelato, R., and D.V. Spracklen. 2007. Carbon mitigation by biofuels or by saving and restoring forests? Science 317: 902, 17 August. 
Schäfer, A., J.B. Heywood, H.D. Jacoby and I.A. Waitz. 2009. Transportation in a Climate-Constrained World. Cambridge, MA: MIT Press.

Schipper, L., S. Meyers, R.B. Howarth, and R. Steiner. 1992. Energy Efficiency and Human Activity: Past Trends, Future Prospects. Cambridge University Press.

Searchinger, T., et al. 2009. Fixing a critical climate accounting error. Science 326: 527-28, 23 October.

Searchinger, T. 2010. Biofuels and the need for additional carbon. Env. Res. Lett. 5, http://dx.doi.org/10.1088/1748-9326/5/2/024007

Singh, M., and M. Mintz. 1997. Alternative Transportation Fuels and Vehicles: Transition Issues and Barriers. Chapter 6 in J. DeCicco and M. Delucchi (eds.), Transportation, Energy, and the Environment: How Far Can Technology Take Us? Washington, DC: American Council for an Energy-Efficient Economy.

Sutherland, I.J. 2010. U.S. Light Duty Transportation Greenhouse Gas Reduction. Technical Report R\&D 12218. Warren, MI: General Motors Research \& Development Center. April.

TRB. 2009. Driving and the Built Environment: The Effects of Compact Development on Motorized Travel, Energy Use, and $\mathrm{CO}_{2}$ Emissions. Transportation Research Board Special Report No. 298. Washington, DC: National Academies Press. www.nap.edu/catalog.php?record_id=12747

Unger, N., et al. 2009. Attribution of climate forcing to economic sectors. Proc. Nat. Acad. Sci., 107(8): 3382-87. www.pnas.org/cgi/doi/10.1073/pnas.0906548107

van Vuuren, D.P., and K. Riahi. 2011. The relationship between short-term emissions and long-term concentration targets. Climatic Change 104: 793-801. doi:10.1007/s10584-010-0004-6.

Vicuna, S. 2004. Exploring Greenhouse Gas Reduction Options for Automobiles: A Report on the International Vehicle Technology Symposium. New York: Environmental Defense, April. http://cleartheair.edf.org/documents/3653 SymposiumReport final.pdf

Waggoner, P.E., and J.H. Ausubel. 2002. A framework for sustainability analysis: a renovated IPAT identity. Proc. Nat. Acad. Sci. 99(12): 7860-65.

Wang, M.Q., et al. 2011. Energy and greenhouse gas emission effects of corn and cellulosic ethanol with technology improvements and land use changes. Biomass \& Bioenergy 35(5): 1885-96. http://dx.doi.org/10.1016/j.biombioe.2011.01.028

Ward's. 2010. Motor Vehicle Facts \& Figures 2010. Southfield, MI: Ward's Automotive Group.

WBCSD. 2004. Mobility 2030: Meeting the Challenges to Sustainability. Geneva: World Business Council for Sustainable Development www.wbcsd.org. 